East African Medical Journal Vol. 86 No. 2 February 2009

REACTIVE LOCALISED INFLAMMATORY HYPERPLASIA OF THE ORAL MUCOSA

D. O. Awange, BDS (Nbi) MMed Sc (Sheffield), Senior Lecturer, K. A. Wakoli, BDS (Nbi) MSc (London), Lecturer, Department of Oral Pathology and Oral Medicine, J. F. Onyango, BDS (Nbi) MSc, FDS RCS (London), Senior Lecturer, M. L. Chindia, BDS (Nbi) MSc (London), FFD RCS (Ireland), Associate Professor, Department of Oral and Maxillofacial Surgery, E.O. Dimba, BDS (Nbi) PhD (Bergen), Assistant Lecturer, Department of Oral Pathology and Oral Medicine and S.W. Guthua, BDS (Nbi) MMed Sci, FIOAMS, DOMS (Havard- MGH) FCS., Professor, Department of Oral and Maxillofacial Surgery, School of Dental Sciences, University of Nairobi, P. O. Box 19676- 00202, Nairobi, Kenya

Request for reprints to: Dr. D.O. Awange, Department of Oral Pathology and Oral Medicine, School of Dental Sciences, University of Nairobi, P. O. Box 19676- 00202, Nairobi, Kenya

\title{
REACTIVE LOCALISED INFLAMMATORY HYPERPLASIA OF THE ORAL MUCOSA
}

\author{
D.O. AWANGE, K. A. WAKOLI, J. F. ONYANGO, M.L. CHINDIA, E.O. DIMBA and S.W. GUTHUA
}

\begin{abstract}
Objective: To document the histopathological pattern and distribution of reactive localised inflammatory hyperplastic lesions of the oral mucosa diagnosed at the University of Nairobi Dental Hospital over a 14 year period.

Design: A retrospective, cross-sectional descriptive study.

Setting: Division of Oral Pathology and Oral Medicine, histopathology laboratory, School of Dental Sciences, University of Nairobi.

Subjects: A total of 3135 oral biopsies were accessioned in the oral diagnostic histopathological Laboratory registry over a period of 14 years from March 1991 to December 2005.

Results: Three hundred and thirty three cases were histopathologically diagnosed as reactive inflammatory hyperplasias of the oral mucosa. This constituted $10.6 \%$ of the total oral biopsy specimens analysed during this period. Fibrous epulis was the most common histological sub-type with 129 cases $(38.7 \%$ ) followed by pyogenic granuloma with $94(28.3 \%)$ cases. Six $(1.8 \%)$ caseswere peripheral giant cell granuloma and three cases $(0.9 \%)$ were those of denture irritation hyperplasia. The age distribution ranged from 2 to 78 years( mean $=30.5$ years) with a peak at 20-29 years. Gender distribution showed that $107(32 \%)$ cases occurred in males and $226(68 \%)$ cases females. Similar trends were observed in most of the histological sub-types. Fibrous epulis occurred in 41 male $(31.8 \%)$ cases and in $88(68.2 \%)$ females with an age range of 2 to 78 years ( mean $=30.5$ years). As for the pyogenic granuloma, $26(27.7 \%)$ lesions occurred in males and $68(72.3 \%)$ in females with an age range of 2 to 75 years ( mean $=30.1$ years). Among all the histopathological sub-types it was shown that $223(67.0 \%)$ cases were fibrous, $104(31.2 \%)$ vascular and six (1.8\%) peripheral giant cell granuloma. Gingival lesions were the most common with $257(77.2 \%)$ cases followed by $28(8.4 \%)$ in the tongue, $16(4.8 \%)$ lips, $15(4.5 \%)$ cheek, six $(1.8 \%)$ palate and the rest on the floor of the mouth and other mucosal sites. The duration of these lesions was recorded in $182(54.7 \%)$ cases and ranged from 1 week to 16 years (mean=1.8 years). Only $15(4.5 \%)$ cases were reported to have recurred and all of them were gingival lesions.

Conclusion: The present study has shown that the prevalence of reactive localised inflamatory hyperplasia (RLIHs) of the oral mucosa was $10.6 \%$ with fibrous epulis and pyogenic granuloma having been the most common histopathological sub-types predominantly affecting females. Although RLIHs are distinguished on clinical or histopatholocal grounds, it is important to appreciate that they are variations of the same basic process.
\end{abstract}

\section{INTRODUCTION}

The term "reactivelocalised inflammatoryhyperplasia" (RLIH) has been used to describe lesions such as pyogenic granuloma/pregnancy tumour, calcifying fibroblastic granuloma, peripheral ossifying fibroma, fibrous epulis, fibro-epithelial polyp, fibrous hyperplasia, denture irritation hyperplasia and peripheral giant cell granuloma (1- 7). RLIHs are commonly encountered oral lesions in humans (8). 
They are usually responses to chronic inflammation caused by various forms of low grade chronic irritations to the oral mucosa such as dental plaque and calculus, sharp edges of grossly carious teeth, faulty dental restorations, chronic biting habits, ill-fitting dental / oral appliances and food impactions (1-4,6-8). Apart from local chronic irritations, these lesions appear to be aetiologically related to systemic factors such as hormonal changes $(6,9-11)$. An essential feature of chronic inflammation is that the processes of inflammation and repair occur simultaneously with the resultant production of granulation tissue and, therefore, most of these lesions represent exuberant production of granulation tissue in chronic inflammatory reactions (1-4). The clinical features of these lesions, therefore, appear to reflect the various stages of development since in the early stages they appear red, raw with ulcerated surfaces and bleed on slight touch or spontaneously, while in the late stages, they appear as firm, mature and avascular fibrous growths which may be sessile, pedunculated or leaf-like in shape (1-4,8,12). Histologically, there is also a wide spectrum of changes varying from chronically, richly cellular granulation tissues to relatively noninflammed and avascular masses of collagen (1-4,8, 12). The purpose of this paper is to document the occurrence, distribution and clinicopathological features of RLIHs at a teaching hospital in Kenya.

\section{MATERIALS AND METHODS}

This study was conducted in the Division of Oral Pathology and Oral Medicine at the University of Nairobi, Dental Hospital in Kenya. The histopathological register and clinical records were examined to extract all entries made as RLIHs from March 1991 to December 2005. The information regarding age, gender, site of the lesion, clinical and histopathological features as well as management were then assessed and tabulated accordingly. All the lesions had been histopathologically analysed by two oral histopathologists employing the haematoxylin and eosin techniques.

\section{RESULTS}

A total of 3135 oral biopsies had been analysed over the period of 14 years among which 333 were histopathologically diagnosed as RLIHs of the oral mucosa. This constituted $10.6 \%$ of all the biopsy specimens seen during this period. The distribution of the RLIHs of the oral mucosa reveals that fibrousepulis was the most common histological sub-type with 129 $(38.7 \%)$ cases followed by pyogenic granuloma with $94(28.3 \%)$ cases while six $(1.8 \%)$ cases were peripheral giant cell granuloma (PGCG) and three $(0.9 \%)$ cases were those of denture irritation hyperplasia (Table 1). The distribution of RLIHs by age and gender (Figure 2 ), indicates that the age distribution ranged from two to 78 years (mean $=30.5$ years) with a peak age of 20-29 years. Gender distribution indicates that 107 (32\%) cases occurred in males and $226(68 \%)$ females. Similar trends were observed in most of thehistological sub-types. Fibrousepulis showed that $41(31.8 \%)$ cases occurred in males and $88(68.2 \%)$ cases females with an age range of $21 / 2-78$ years (mean $=30.5$ years). In pyogenic granuloma, $26(27.7 \%)$ cases occurred in males and $68(72.3 \%)$ in females with an age range of two to 75 years (mean 30.1 years).

Table 1

Distribution of the histopathological subtypes of RLIHs of the oral mucosa

\begin{tabular}{|c|c|c|c|c|c|c|}
\hline Type of lesion & No. of cases & $(\%)$ & Male & Female & Age range & Mean \\
\hline Pyogenic granuloma & 94 & 28.3 & 26 & 68 & $2-75$ & 30.1 \\
\hline Pregnancy tumour & 10 & 3.0 & 0 & 10 & $18-46$ & 26.2 \\
\hline Fibrous epulis & 129 & 38.7 & 41 & 88 & $2^{1} / 2^{-78}$ & 30.5 \\
\hline Fibro-epithelial polyp & 38 & 11.4 & 15 & 23 & $2-70$ & 29.9 \\
\hline Fibrous hyperplasia & 41 & 12.3 & 17 & 24 & $3-76$ & 28.0 \\
\hline \multicolumn{7}{|l|}{ Peripheral ossifying } \\
\hline Fibroma & 12 & 3.6 & 4 & 8 & $16-56$ & 28.5 \\
\hline \multicolumn{7}{|l|}{ Denture irritation } \\
\hline Hyperplasias & 3 & 0.9 & 2 & 1 & $55-69$ & 59.5 \\
\hline \multicolumn{7}{|l|}{ Peripheral giant cell } \\
\hline Granuloma & 6 & 1.8 & 2 & 4 & $12-40$ & 21.4 \\
\hline Total & 333 & 100 & 107 & 226 & & \\
\hline
\end{tabular}


Figure 2

Distribution of RLIHs according to age and gender

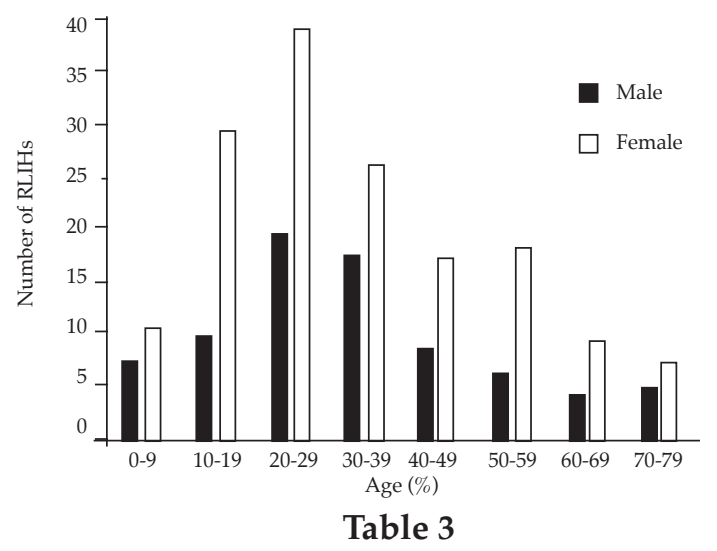

Site distribution of RLIHs of the oral mucosa

\begin{tabular}{lcc}
\hline Site & No. & $(\%)$ \\
\hline Gingiva & 257 & 77.2 \\
Tongue & 28 & 8.4 \\
Lip & 16 & 4.8 \\
Cheek & 15 & 4.5 \\
Palate & 6 & 1.8 \\
Floor of the mouth & 2 & 0.6 \\
Others & 9 & 2.7 \\
\hline Total & 333 & 100 \\
\hline
\end{tabular}

Thehistopathological subtypes showed that 223 cases $(67 \%)$ were fibrous, $104(31.2 \%)$ vascular and $\operatorname{six}(1.8 \%)$ peripheral giant cell granuloma. Table 3 summarises the information regarding the site distribution of the lesions in the oral mucosa. Gingival lesions were the most common with $257(77.2 \%)$ cases followed by $28(8.4 \%)$ in the tongue, $16(4.8 \%)$ lips, $15(4.5 \%)$ cheek, six $(1.8 \%)$ palate and the rest in the floor of the mouth and other mucosal site. Of the 257 gingival lesions $147(57.2 \%)$ were located anteriorly (incisor-canine area), $43(16.7 \%)$ premolar, $57(21.2 \%)$ molar and the rest $10(3.9 \%)$ retromolar areas. The duration over which these lesions had manifested was recorded in 182 cases $(54.7 \%)$ and ranged from one week to 16 years $($ mean $=1.8$ years). Only 15 cases $(4.5 \%)$ were reported to have recurred, all of which were gingival lesions.

\section{DISCUSSION}

There are currently no large series that demonstrate the pattern of occurrence of RLIHs of the oral mucosa in Kenya. This study reveals an overral incidence of $10.6 \%$ of the total oral biopsies at our institution over a period of 14 years which is in agreement with previous studies $(5,8,11,13-15)$. Nartley et al. (9) reported an incidence of $10.3 \%$ and Zain and Vei (14) found $9.6 \%$ of the total oral biopsies in their respective studies. In our study, the most common RLIHs of the oral mucosa was fibrous epulis with 129 $(38.7 \%)$ cases followed by pyogenic granuloma with $94(28.3 \%)$ cases and more females than males were affected. These observations were similar to those in previous studies $(5,6,11,13,14)$, however, a male predilection was noted in cases of fibrous epulis in a previous study (9). The majority of RLIHsin thisstudy affected patients in their second and third decades of life with a peak age of 20-29 years. The age range of fibrous epulis was from $2^{1} / 2$ to 78 years (mean $=30.5$ years) and two to 75 years (mean=30.1 years) for pyogenic granuloma. While this was in agreement with previous studies $(6,9,11,13,-15)$, it differs from the observation by Angelopoulus (10) who recorded the highest prevalence (23.9\%) between 10 and 20 years of age and Wayli and Mosadomi (8) who observed the highest prevalence of $40 \%$ between 30 and 40 years of age. The site distribution in this study indicated that the gingival margins were more commonly involved with $257(77.2 \%)$ cases than any other mucosal sites. The anterior incisor-canine segments were the most preferred as compared to the posterior segments of the gingival margins. In the studies done elsewhere, $71 \%$ (9) and $87.09 \%$ (8) of RLIHs respectively were reported in the gingival margins and the rest in other mucosal sites. Theincreased incidence of RLIHs in the anterior incisor-canine segments may be attributed to the increased concentration of chronic irritation factors such as calculus and plaque in the gingival margins and more particularly in the anterior regions.

RLIHs may not be life threatening conditions but may constitute an important index of general health and oral hygiene. The prevalence and distribution of RLIHs is supposed to reflect the oral hygiene standard and factors that may render oral tissues more susceptible to chronic irritation. In the present study, $28.3 \%$ were pyogenic granuloma and the majority of those afflicted (72.3\%) werefemales. Wayli and Nartley et al (8) reported $24.75 \%$ of pyogenic granuloma among which were three pregnancy tumours. Angelopoulus (10) and Kfir et al (6) had suggested that the age incidence and the females predilection in their series reflected the influence of pregnancy in the pathogenesis of the diseases. Daley et al. (11) also observed the positive incidence of localised inflammatory hyperplasia especially pyogenic granuloma and serum progesterone and oestrogen concentration in pregnant women. Nartley et al. (9) speculated in their series that the two hormones may render the gingival tissues more susceptible to chronic irritation by plaque and calculus. It is also mentioned in the literature that the oral contraceptive drug is an aetiological factor in pregnancy tumour (16).

Histopathologically, there is an overlap among the entities of RLIH's that appear to represent the same lesions at different stages of development (1-4). The predominant vascular lesion including 
pyogenicgranuloma, pregnancy tumour or calcifying fibroblastic granuloma may mature and develop into a more fibrous lesion such as fibrous epulis, fibrous hyperplasia, fibroepithilial polyp, peripheral ossifying fibroma and denture irritation hyperplasia $(1-3,6,12,15-17)$.

In our study, fibrous lesions constituted (67\%), vascular lesions (31.2\%) and PGCG (1.8\%). Denture irritation hyperplasias are usually associated with ill-fitting or rocking prostheses and may be along the flanges or may be flattened and appear leaf-like in shape (2-4). In the present study, only three (0.9\%) cases of denture irritation hy perplasia were observed in elderly patients with an age range of 55 to 59 years. PGCG constituted only six $(1.8 \%)$ cases in this study, all occurring in the gingival margin of patients between $12-40$ years (mean=21.4 years). PGCG is a multinucleated giant cell lesion which clinically appears as a dark or purplish red swelling on the gingival margins or alveolar mucosa. Its aetiology is not known but trauma to the periosteum has been implicated (1-4). In a previous study (9), only 10 cases $(6 \%)$ of PGCG were reported with an age of 10 to 51 years.

Although the mean ages for various lesions or different histopathological entities in this study ranged from 21.4 years to 59.5 years, they are reactive mucosal lesions consequent to low grade irritations and their varied histological appearances probably reflect the severity of the irritation, duration of the lesion and hormonal changes $(2-4,7-9,16)$. The duration of RLIHs of the oral mucosa was given in $182(54.9 \%)$ cases and ranged from 1 week to 16 years. The results of this study are not in agreement with those of Angelopoulus (10) who observed a mean of 8.6 months and Wayliand Mosadomi (8) who reported a mean of 7.5 months in their respective studies. The recurrence rate of $4.5 \%$ observed in this study was higher than $1.6 \%$ reported by Mcleod and Soames (15) but falls below others which range between $8.4 \%$ $-20 \%(7,14,18)$. The low rate of recurrence may reflect either effective management of the lesions or lack of proper follow-up.

\section{ACKNOWLEDGEMENTS}

To the Dean and the entire administration of the School of Dental Sciences for permission to execute this study. We are indebted to Mrs. Alice Limo and Mr. Josiah Otuoma for their technical assistance in the preparation of the histopathological material for analysis. Finally we most sincerely thank Ms. Terry Aholi for secretarial services.

\section{REFERENCES}

1. Cawson, R. A. and Odell, E.W. Cawson's Essentials of Oral Pathology and Oral medicine 7th Edition - Churchill, Livingstone. 2002 pp 275-280.

2. Southam, J.C. and Soames, J. V. Oral pathology 3rd Edition. Oxford Medical Publications, Oxford, New York, Tokyo 1998.

3. Regezi, A.J. and Sciubba, J. J. Oral pathology-clinicalpathological Correlations. 4th Edition. WB Saunders Company. Philadelphia. 2003 pp157-182.

4. Neville, B.W. Damn, D.D., Allen, C. M. and Bouquot, J.E. Oral and maxillofacial pathology 1st edition W.B Saunders Company, Philadelphia, Pennylslvania. 1995 pp 362-384.

5. Zain, R.B. and Jin, Yeo. Fibrous lesions of the gingiva: A histopathologocal analysis of 204 cases: Oral Surg. 1990; 70: 466-470.

6. Kfir, Y., Buchner, A. and Hansen, L.S. Reactive lesions of the gingiva: A clinicopathological study of 741 cases. J. Periodontal.1980; 51: 55-61.

7. Eversole, L.R. and Rovin, S. Reactive lesions of the gingiva. J. Oral Path. 1972; 1: 30-38.

8. Wayli, A,H. and Mosadomi, A,H. Pyogenicgranuloma among Saudi females in an outpatient dental clinic. The Saudi Dent. J. 2006; 18: 105-110.

9. Nartley, N.O, Mosadomi, H A, AI-Gailani M. and AI-Mobeerik. A. Localised inflammatory hyperplasia of the oral cavity:Clinico-pathological study of 164 cases. The Saudi Dental J. 1994, 6: 145-150.

10. Angelopoulous, A.P. Pyogenic granuloma of the oral cavity: Statistical analysis of its clinical features. J. Oral Surg. 1997; 29: 840-847.

11. Daley, T.D., Wysocki, G.P. and Wysocki, D. M. The major Epulides. Clinicopathological correlations. J. Can. Dent. Ass. 1990; 56:627-630.

12. Baker, D.S. and Lucas, R.B. Localized fibrous overgrowth of the oral mucosa. J. Dent. Res. 1965; 44: 1160.

13. Buchner, A., Calderon, S. and Ramon, Y. Localized hyperplasticlesions of the gingiva: A clinicopathologic study of 302 lesions. J. Periodontics: 1974; 48: 101-104.

14. Zain, R.B. and Vei, T.J. Peripheral fibroma/fibrous epulis with or without calcifications. A clinical evaluation of 204 cases in Singapore. Trop. Dent. J. 1990; 3: 94 - 96.

15. Mcleod, R.I. and Soames, J.V. Epulides: A clinicopathological study of a series of 200 consecutive lesions. Brit. Dent. J.1987; 163: 51-53.

16. Koufman, A.Y. An oral contraceptive as an aetiologic factor in producing hyperplastic gingivitis and a neoplasm of pregnancy tumor type. Oral. Surg. 1969; 28: 266.

17. Basker, S.N. and Jacoway, I. R. Peripheral fibroma and peripheral fibroma with calcifications. Report of 376 cases. J. Am. Dent. Ass. 1966; 131: 1320- 1322.

18. Lee, K.W. The fibrous epulis and related lesions. Periodontics. 1986;16:277-299. 